II Congresso Brasileiro de

Fluidodinâmica Computacional

27 a 29 de Junho de 2018

Rio de Janeiro, RJ

\title{
APLICAÇÃO DA FLUIDODINAMICA COMPUTACIONAL PELO IDQBRN
}

\author{
C. E. S. BONFIM ${ }^{1}$, P. A. M. CABRAL ${ }^{1}$, T. BRUM ${ }^{1}$, F. OUGANO ${ }^{1}$, \\ ${ }^{1}$ Instituto de Defesa Química, Biológica, Radiológica e Nuclear, Seção de Defesa Química \\ E-mail para contato: bonfim.carlos@eb.mil.br
}

\begin{abstract}
RESUMO - A Simulação Computacional é uma ferramenta com um campo de aplicação muito grande e que permeia por diversas áreas do conhecimento. O uso da Fluidodinâmica Computacional na Defesa Química, Biológica, Radiológica e Nuclear (QBRN), constitui uma poderosa ferramenta para auxiliar e assessorar de forma técnica e científica as ações de Defesa quais o Instituto de Defesa Química, Biológica, Radiológica e Nuclear (IDQBRN) está inserido.
\end{abstract}

\section{INTRODUÇÃO}

Em setembro de 2001, com o ataque às torres gêmeas nos EUA, a Defesa Química, Biológica, Radiológica e Nuclear (DQBRN) cresceu vertiginosamente no Brasil e no mundo. A partir deste momento, os EUA iniciaram a Guerra contra o Terror. Embora os atos terroristas sempre tenham ocorrido em diferentes lugares e em momentos diferentes, foi desde 2001 que houve uma intensificação clara deste tipo de ataque, de acordo com a base de dados global de terrorismo (Global Terrorism Database), como mostrado por BARBOSA (2011). E uma variável que acrescenta ainda mais terror a esses ataques de violência extrema é o uso de agentes QBRN. Por isso, é imprescindível que os Organismos de Defesa estejam preparados para detectar e identificar os tipos de agentes empregados e decidir quais ações tomar para minimizar as consequências do uso de Agentes QBRN com respostas eficientes e eficazes. Neste contexto, a Dinâmica de Fluidos Computacionais (CFD) pode ser empregada para prever diferentes cenários envolvendo o uso de agentes QBRN. Técnicas de CFD têm sido amplamente utilizadas onde a simulação tem sido útil para desenvolver produtos de qualidade, medir a eficiência de equipamentos de alto desempenho, adaptar e melhorar as condições e planos operacionais, otimizar a instalação de sensores e detectores.

Diante disso, a Dinâmica dos Fluidos Computacionais foi incluída na lista de projetos de interesse estratégico da Defesa Nacional, elaborados conjuntamente pelos Ministérios da Defesa e da Ciência, Tecnologia, Inovação e Comunicações. Além disso, foi realizada a apresentação de uma proposta ao Ministério da Defesa para o desenvolvimento técnicocientífico da CFD na área da Defesa QBRN, descrito por VIANNA, (2014).

\section{DESENVOLVIMENTO}

O Laboratório de Modelagem de Consequências e Análise de Riscos (LAMCAR) do IDQBRN, por meio das simulações numéricas, permeia pelas 03 (três) áreas de Defesa do Instituto 


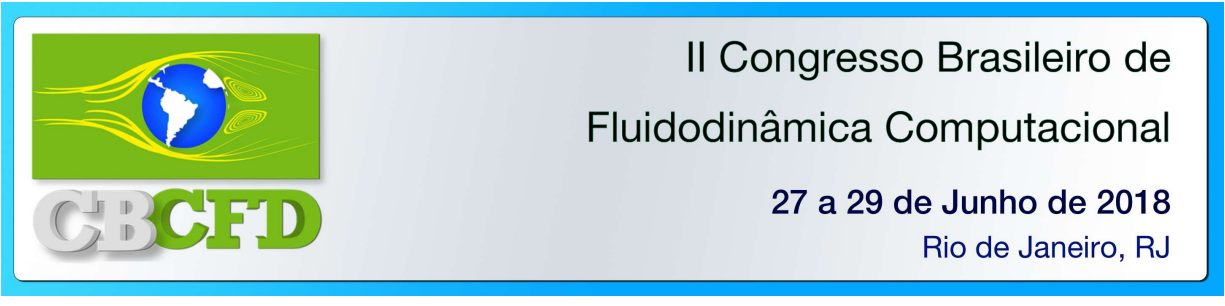

(Química, Biológica, Radiológica e Nuclear), abaixo segue alguns casos de aplicação no campo de Fluidodinâmica Computacional no âmbito tecnológico do Exército.

\section{a. Leito de Jorro}

Necessidade de verificar padrões de escoamento (fluidodinâmicos), de modo a obter, comparar e otimizar parâmetros como coeficiente de arraste (queda de pressão), empacotamento de partículas, geometria do leito, vazão de fluido (gás inerte), concentra de gás de pirólise, conforme Figuras 1 e 2, encontrado em CABRAL (2007).
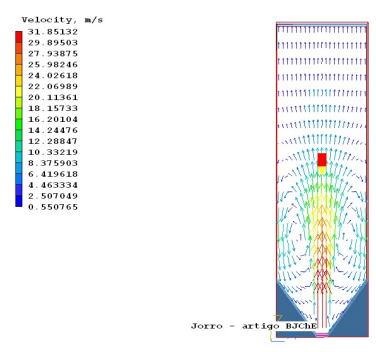

Figura 1: Linhas de corrente



Figura 2: Trajetória de partículas

b. Tubeira do Míssil MSA (Míssil Solo-Ar)

Necessidade de realizar simulações visando a otimização de parâmetros de construção da tubeira/garganta do míssil: diâmetros da garganta e entrada/saída da tubeira, ângulos de convergência e de divergência, comprimento da tubeira, de acordo com as Figuras $3,4,5$ e 6 ;

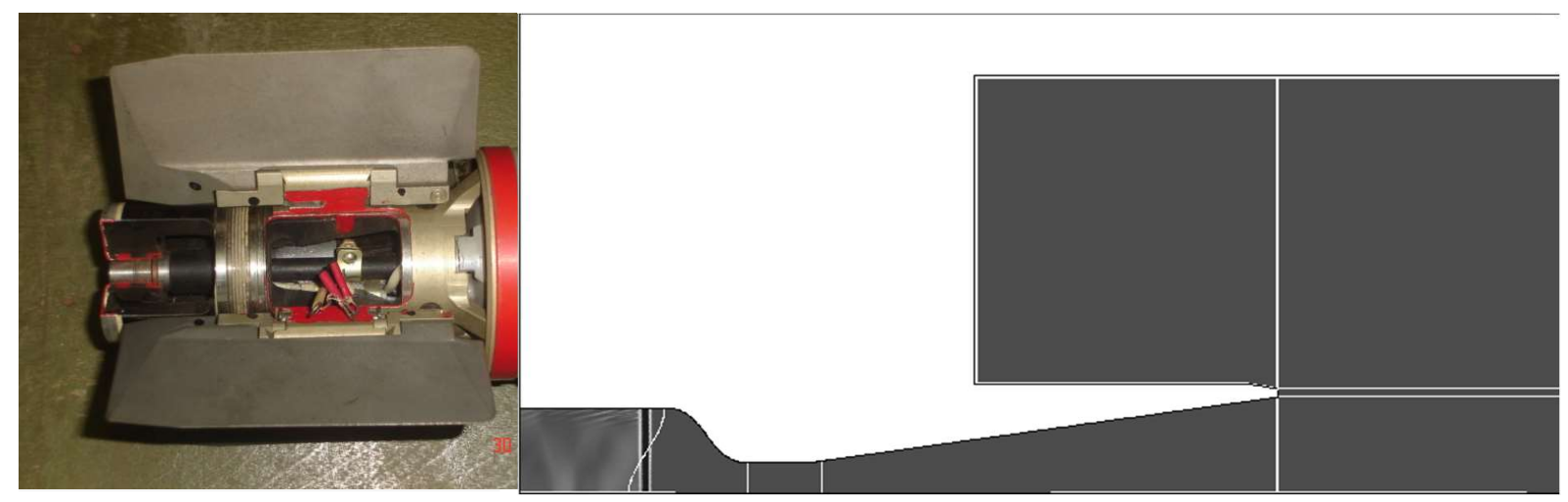

Figura 3: Turbina MSA

Figura 4: Perfil de Pressão 


\section{Congresso Brasileiro de}

Fluidodinâmica Computacional

27 a 29 de Junho de 2018

Rio de Janeiro, RJ

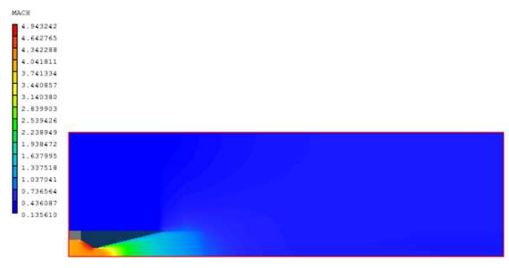

Figura 5: Perfil de $\mathrm{n}^{\circ}$ Mach externo

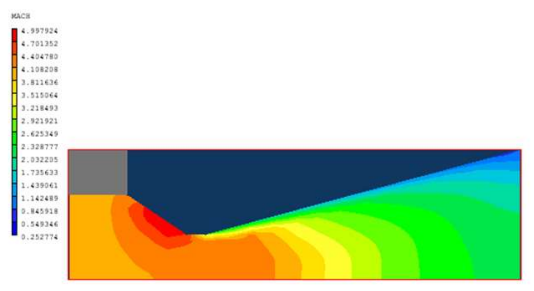

Figura 6: Perfil de $\mathrm{n}^{\circ}$ Mach Interno

c. Incorporação de mapas digitais aos modelos de predição

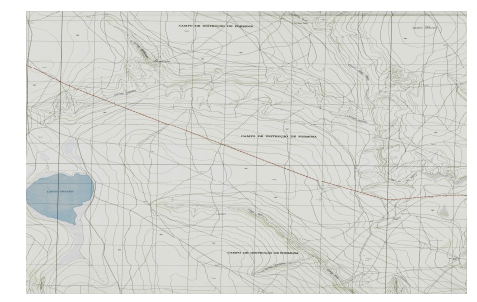

Figura 7:Mapa digital

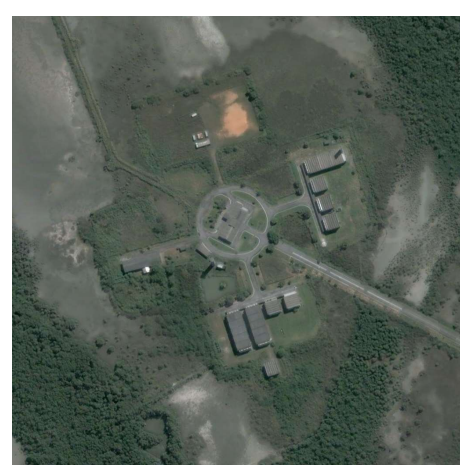

Figura 8: Foto aérea IDQBRN

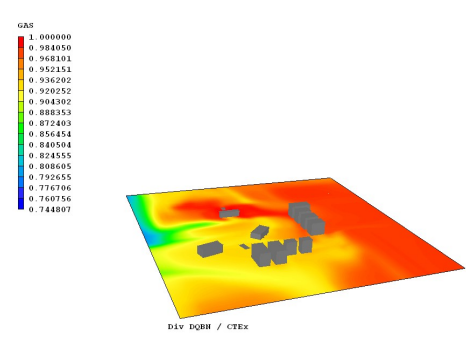

Figura 9: Simulação

\section{CONCLUSÃO}

Os casos apresentados referem-se a projetos já encerrados em que o uso do CFD foi de extrema importância para melhoria do projeto.

- Atualmente o IDQBRN, por intermédio do LAMCAR, conta com as seguintes linhas de pesquisa:

- Simulação de plumas oriundas de dispersão química, biológica e plumas radioativas, acopladas ao Sistema COBRA, utilizado pelo Exército Brasileiro nos Grandes Eventos, Figura 10;

- Análise de Plumas radioativas usando dados experimentais da CTBTO (Comprehensive Nuclear-Test Ban Treaty Organization);

- Simulação da difusão de materiais industriais tóxicos em bacias, rios, sistema de distribuição de água, estimativa de concentração de contaminação, comportamento difusivo no meio ambiente;

- Simulação e analise de dispersão de agente biológico (bacilus antraz) em ambiente fechado. 

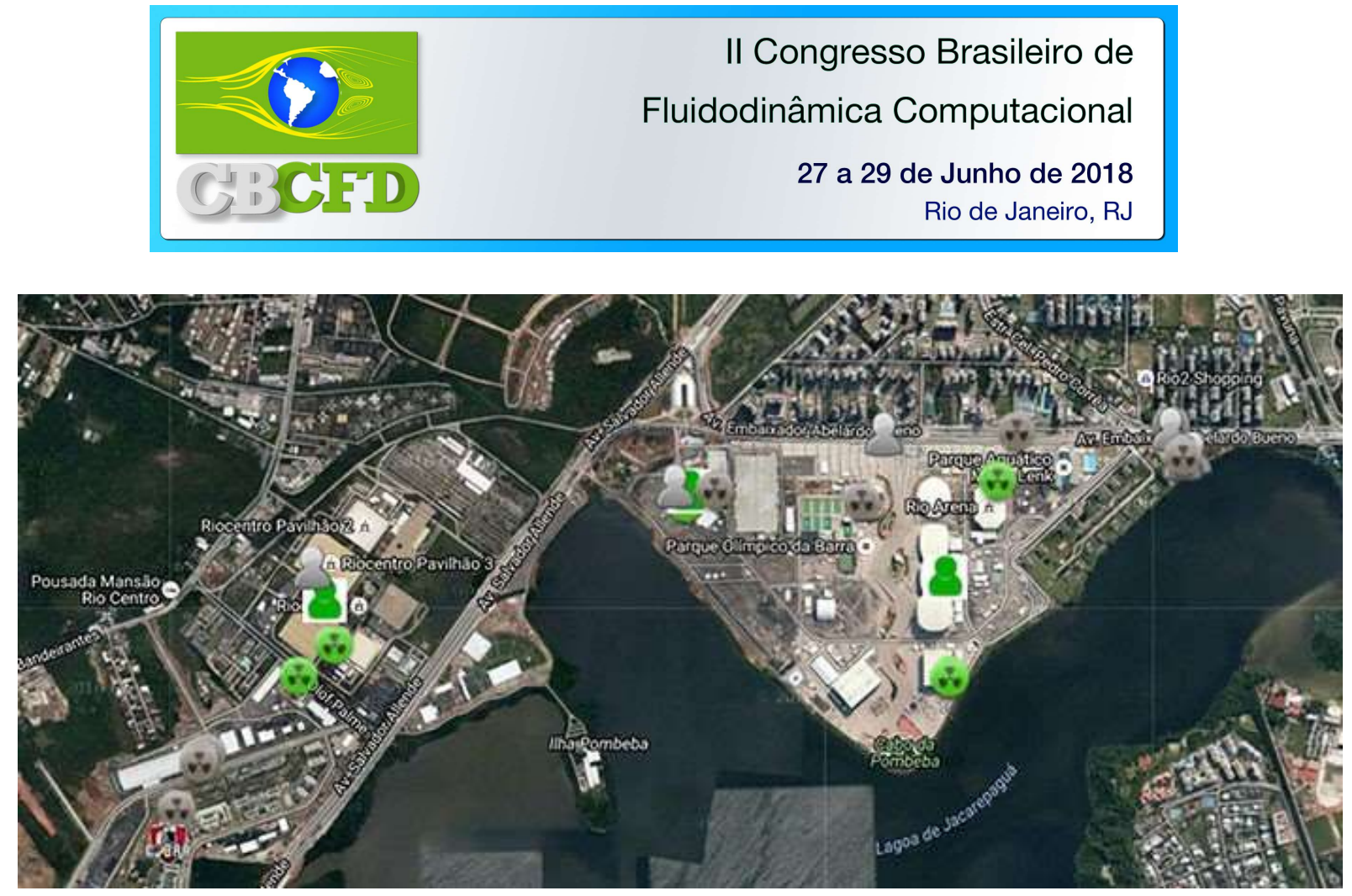

Figura 10: Imagem do sistema COBRA, mostrando os detectores ativos em tempo real

\section{REFERÊNCIAS}

1. BARBOSA, R. A. Os Estados Unidos pós 11 de setembro de 2001: implicações para a ordem mundial e para o Brasil. Rev. bras. polit. int. [online]. 2002, vol.45, n.1, pp.72-91. ISSN 19833121.

http://dx.doi.org/10.1590/S003473292002000100003. http://www.scielo.br/scielo.php?script $=$ sci_arttext\&pid=S0034-73292002000100003\&lng=pt\&tlng=pt. Acesso em: 10/07/2017.

2. VIANNA Jr., A. S. et al., CFD e Defesa Química, Revista Virtual de Química, 2014, 6, 815.

3. Portaria no 204 EME, de 14 de dezembro de 2012. Aprova a Diretriz para Atualização e Funcionamento do Sistema de Defesa Química, Biológica, Radiológica e Nuclear do Exército.

4. Portaria n ${ }^{\circ} 228$-EME, de 28 de setembro de 2015. Aprova a Diretriz para a Implantação do Instituto de Defesa Química, Biológica, Radiológica e Nuclear (EB20D-07.046)

5. Wolff Filho, Germano Klaus, \& Cabral, Paulo Alexandre de Moraes . (2007). CFD simulations of a spouted bed equipment for particle coating. Proceedings of the INAC 2007 International nuclear atlantic conference Nuclear energy and energetic challenges for $21 \mathrm{st}$ century 15 Brazilian national meeting on reactor physics and thermal hydraulics; 8 Brazilian national meeting on nuclear applications, (p. v). Brazil 